\title{
THERMAL DEGRADATION OF
}

\author{
POLY( $\alpha$-METHYLSTYRENE)
}

IN SOLUTION

submitted to
Polymer Degradation and Stability

by

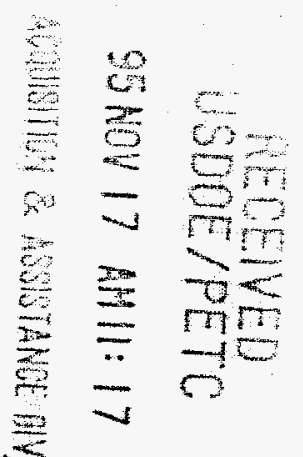

Giridhar Madras, J.M. Smith, and Benjamin J. McCoy"

Department of Chemical Engineering and Materials Science

University of California

Davis, CA 95616

\footnotetext{
- Author to whom correspondence should be addressed. bjmccoy@ucdavis.edu. Fax : (916) 752-1031.
} 


\title{
Abstract
}

The thermal degradation of poly( $\alpha$-methylstyrene) in solution was investigated at various temperatures $(150-225 \mathrm{C})$ and polymer concentrations $(2.00-20.0 \mathrm{~g} / \mathrm{L})$ at $6.8 \mathrm{MPa}$ (1000 psig). The molecular weight distributions (MWDs) of the reacted polymer at these conditions were examined at four different residence times. Experimental data indicated that the polymer degraded to its monomer, $\alpha$-methylstyrene. No other degradation products were observed. Continuous-mixture kinetics was used to examine the MWDs and to obtain the rate coefficient for degradation and its activation energy. The rate was first-order in polymer concentration with a rate constant at $225 \mathrm{C}$ of $0.01 \mathrm{~min}^{-1}$ and an activation energy of $66.5 \mathrm{~kJ} / \mathrm{mol}(16.0 \mathrm{kcal} / \mathrm{mol})$. The maximum conversion observed at $275 \mathrm{C}$ was $1.2 \%$.

Hydrogen-donor solvent, tetralin, had no effect on the degradation.

\section{DISCLAIMER}

\begin{abstract}
This report was prepared as an account of work sponsored by an agency of the United States Government. Neither the United States Government nor any agency thereof, nor any of their employees, makes any warranty, express or implied, or assumes any legal liability or responsibility for the accuracy, completeness, or usefulness of any information, apparatus, product, or process disclosed, or represents that its use would not infringe privately owned rights. Reference herein to any specific commercial product, process, or service by trade name, trademark, manufacturer, or otherwise does not necessarily constitute or imply its endorsement, recommendation, or favoring by the United States Government or any agency thereof. The views and opinions of authors expressed herein do not necessarily state or reflect those of the United States Government or any agency thereof.
\end{abstract}




\section{Introduction}

The study of degradation and stabilization of polymers is important both from practical and theoretical viewpoints 1 . Among the various applications, degradation can be used to recycle waste plastics ${ }^{2}$, and in conjunction with chromatography to characterize polymeric structure ${ }^{3}$. Early investigations centered on investigating the yield of monomer ${ }^{4}$, and rate of change of average molecular weight. The rate equations were typically based on free-radical mechanisms 5 . A few other studies addressed the kinetics of polymer degradation quantitatively by combining theoretical and experimental investigations 6-8. These studies involved experimental parameters for intermediate and final products.

Though thermal degradation has been investigated extensively under pyrolysis conditions $9-10$, commercial application has been hindered due to low heat transfer rates and high viscosity of the melting polymer. Reactor design is also complicated because degradation rates depend on reactor geometry and stirring rates 11 . Though thermal degradation in solution is less affected by these problems, there have been few studies of such solution processes. Recently, degradation of polystyrene ${ }^{12}$, poly $(\alpha \text {-methylstyrene })^{13}$, and poly(pmethylstyrene $)^{14}$ was studied in various solvents. Degradation of poly $(\alpha-$ methylstyrene) was observed to be independent of the solvent, while for other polymers the process was affected by the solvent. These studies did not determine the rate coefficients or their dependence on temperature. In our laboratory the degradation of poly(styrene-allyl alcohol) ${ }^{15}$ was studied in tbutanol, and also in the presence of a hydrogen-donor solvent, tetralin 16 . The conversion increased with tetralin concentration. Rate coefficients at several temperatures were obtained from the experimental data using continuous-mixture 
kinetics. The activation energy for random scission was $35 \mathrm{kcal} / \mathrm{mol}$, while the energies of activation for the specific products were in the range of $4-8 \mathrm{kcal} / \mathrm{mol}$.

The continuous-mixture concept provides a simple and effective procedure to investigate the kinetics of polymer degradation based on the change in molecular weight distributions (MWDs). Continuous-mixture models have been used to determine the kinetics for the liquefaction of $\operatorname{coal}^{17}$, for oligomerization 18 , and polymer degradation 15 .

The objective of the present work is to determine degradation behavior of poly $(\alpha$-methylstyrene) (PAMS) in toluene at $1000 \mathrm{psig}(6.8 \mathrm{MPa})$ at various temperatures (150-225 C) and to identify specific scission products. The rate coefficients are determined by applying the moment theory to the MWD of the reacted polymer, and the energy of activation is obtained from the temperature dependence of these coefficients.

Compared to other studies, the present approach has certain advantages. Polymer degradation occurs in a single phase, ensuring that the reactants and the products have the same residence time in the steady-flow reactor. The residence time is easily varied by controlling the flow rate. The effluent is analyzed to yield MWD's as a function of time of reaction. As the temperature is uniform for all fluid elements, determining the temperature dependence of the rates is straightforward. Finally, the application of continuous-mixture kinetics provides the mathematical framework for quantitative interpretation of the experimental data 


\section{Experiments}

\section{Pretreatment of PAMS}

PAMS of number average molecular weight 685 (determined by vapor phase oxidation by the manufacturer) was obtained from Aldrich Chemical Company, Inc. The MWD of PAMS was obtained by dissolving $0.0200 \mathrm{~g}$ of PAMS in $10 \mathrm{~mL}$ of tetrahydrofuran (THF) and analyzing the sample by gel permeation chromatography (GPC). The result in Figure 1 indicates a number average $\mathrm{MW}$ of 700 . Figure 1 shows many peaks in the lower $\mathrm{MW}$ range of the raw PAMS that may interfere with the product(s) of reaction. To eliminate these low MW peaks, the polymer was fractionated ${ }^{19}$ by dissolving 50 grams of polymer in $500 \mathrm{~mL}$ of toluene at $35 \mathrm{C}$. Then a sample of $750 \mathrm{~mL}$ of $\mathrm{n}$-butanol, a precipitating agent, was slowly added to this solution. During this process, the solution was continuously stirred and heated to $45 \mathrm{C}$. Approximately 30 grams of the high molecular weight polymer precipitated and was dried in an oven to constant weight. The MWD of the treated polymer is shown in Figure 2, indicating the number-average $\mathrm{MW}$ is 39,100 .

\section{Degradation of PAMS}

The thermal degradation of the treated PAMS in solution was conducted in a steady-state plug-flow reactor at high temperatures and high pressures. Detailed descriptions of apparatus and experimental procedure are provided elsewhere ${ }^{20,21}$. All the experiments were conducted in the liquid phase so that the reaction products remain in solution. The relatively low temperatures result in low conversion and negligible repolymerization. 
Treated PAMS was dissolved in toluene to the desired concentration $(2.00-20.0 \mathrm{~g} / \mathrm{L})$ at $35 \mathrm{C}$. This solution is passed through a tubular-flow reactor maintained at constant pressure, 6.8 $\mathrm{MPa}$. The temperature of the reactor is increased to the desired level by a controller. The solution flows through the high-temperature reactor under pressure, is cooled by a water cool heat-exchanger, and flows through a pressure-reduction valve. The flow rate is controlled by a rotameter placed after the pressure-reduction valve. Thermal degradation experiments at each temperature and polymer concentration are performed at four different flow rates $(6,9$, $12,20 \mathrm{~mL} / \mathrm{min}$ at STP conditions). The residence time in the reactor is calculated by determining the density of the solvent at reactor conditions (using the Lee-Kesler ${ }^{22}$ equation). At each condition, two effluent samples of $10 \mathrm{~mL}$ each were taken for analysis.

\section{Analysis of degradation products}

The sample of $10 \mathrm{~mL}$ is concentrated to $2 \mathrm{~mL}$ by evaporating the toluene at $70 \mathrm{C}$ under vacuum. This remaining liquid is dissolved in THF (Baker Analyzed) and a sample of 100 $\mu \mathrm{L}$ of the solution injected into the GPC coupled with a HPLC (Hewlett-Packard 1050) system. Three PLgel columns (Polymer Lab Inc.) of $300 \mathrm{~mm} \times 7.5 \mathrm{~mm}$ of 100,500 , and $10^{4}$ Å pore size, packed with cross-linked poly(styrene-divinyl benzene) are used in series for efficient separation. The HPLC system consists of a sample loop of $100 \mu \mathrm{L}$, a gradient pump that pumps $\mathrm{THF}$ at a constant flow rate of $1.0 \mathrm{~mL} / \mathrm{min}$, and an on-line $\mathrm{UV}$ detector at $230 \mathrm{~nm}$ for the absorbance of the sample. Various wavelengths were investigated in the range of $220-330 \mathrm{~nm}$, and $230 \mathrm{~nm}$ was chosen because of a strong absorbance and separation of the poly ( $\alpha$-methylstyrene), $\alpha$-methylstyrene, and toluene peaks. GPC measurements were 
also made with ethyl acetate as the solvent and the chromatographs obtained were similar to those obtained with THF as the solvent.

Polystyrene standards (MW ranging from 162 to 1.5 million) from Polymer Lab Inc. were dissolved in THF and injected into the HPLC-GPC for peak position calibration. Styrene and $\alpha$-methylstyrene were dissolved in THF, analyzed in the GPC, and the calibration was extended to lower MW range. The monomer peak was also calibrated quantitatively by injecting known amounts of $\alpha$-methylstyrene in the GPC, yielding a standard deviation of the peak areas of $3-4 \%$.

\section{Mechanism}

The thermal-degradation mechanism for polymers depends on molecular structure and experimental conditions. Two extremes exist, pure random degradation and pure depolymerization. Random degradation of a polymer occurs by bond scission at any position along the chain backbone. Depolymerization occurs by scission at the chain-end, which for homopolymers yields monomers.

For the reacted polymer, Figure 3 shows two distinct peaks in the MWD below 1500 . To identify these peaks, the effluent of the GPC analysis was separated based on retention time, and the samples were analyzed by GC-MS. The GC-MS analysis confirmed that the peak at $\mathrm{MW}=118$ was $\alpha$-methylstyrene. The peak at $\mathrm{MW}=1170$ was positively identified as a non-reaction product, dioctyl phthalate $(\mathrm{MW}=390)$. Due to its molecular size, this compound appears at $M W=1170$. This was confirmed by measuring the retention time of pure dioctyl phthalate (Aldrich Chemical Company, Inc.) in the GPC. Often used as 
a plasticizer ${ }^{23}$, the dioctyl phthalate detaches unreacted from the chain at the reaction temperatures and is nearly constant in amount at all residence times.

Figure 4 compares the polymer portion of Figure 2 and Figure 3. The dioctyl phthalate peak is removed from Figure 4 since it is a non-reaction product. The change in the first moment (which corresponds to the average molecular weight) of the unreacted polymer would be noticeable (even at low conversions) if random scission is significant. Calculations for the curves in Figure 4 show that the first moment of the reacted polymer (MW $=$ $190,000)$ is nearly unchanged from that of the unreacted polymer $(M W=190,200)$ at the experimental conditions of Figure 5. Thus one can conclude that the thermal degradation of PAMS at low conversion is by pure depolymerization with chain-end scission yielding $\alpha-$ methylstyrene according to the reaction :

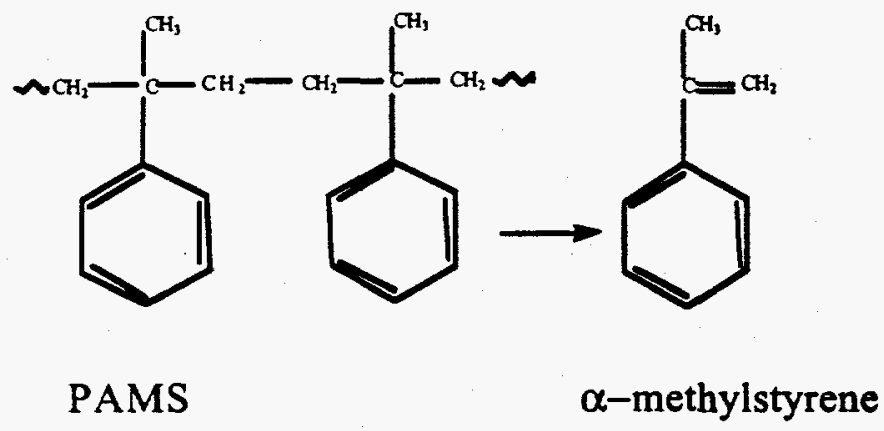

\section{Theoretical Model}

Continuous-mixture kinetics for polymer degradation were used in our earlier work to study the random-chain degradation and chain-end scission of poly(styrene-allyl alcohol) ${ }^{15-16}$. Since no random-chain scission occurs at the low conversions in the present study, a model accounting only for specific chain-end scission is developed. 
The polymer solution is considered to be a complex mixture with a large number of different size molecules, whose distribution is described by a continuous variable such as MW. We define $A(x)$ to be a polymer molecule with molecular weight $x$. With specific degradation to $\mathrm{x}_{1}$ (MW of $\alpha$-methylstyrene), one can write the polymer degradation as $\mathrm{A}\left(\mathrm{x}^{\prime}\right) \rightarrow \mathrm{A}\left(\mathrm{x}_{1}\right)+\mathrm{A}\left(\mathrm{x}^{\prime}-\mathrm{x}_{1}\right)$

The time-dependent MWD of $A(x)$ is defined as $p(x, t)$ based on molar concentration. The rate coefficient of degradation is $k(x)$, and $v\left(x_{1}, x^{\prime}\right)$ is the fraction of $A\left(x^{\prime}\right)$ that cracks to $A\left(x_{1}\right)$. When the reaction is first-order (verified experimentally) two rate equations are required to describe $A\left(x_{1}\right)$ and $A\left(x^{\prime}-x_{1}\right)$.

For $A\left(x^{\prime}-x_{1}\right)$ :

$$
\frac{d p(x, t)}{d t}=-k(x) p(x, t)+\int_{x}^{\infty} k\left(x^{\prime}\right) p\left(x^{\prime}, t\right) v\left(x-x_{1}, x^{\prime}\right) d x^{\prime}
$$

For $\mathrm{A}\left(\mathrm{x}_{1}\right)$ :

$$
\frac{d q_{1}\left(x_{1}, t\right)}{d t}=\int_{x}^{\infty} k\left(x^{\prime}\right) p\left(x^{\prime}, t\right) v\left(x_{1}, x^{\prime}\right) d x^{\prime}
$$

Here, $q_{1}\left(x_{1}, t\right)$ is the MWD of the specific product $\alpha$-methylstyrene of $M W x_{1}$. The rate coefficient $k(x)$ generally depends on $x$. However, Wang et al. ${ }^{15}$, Madras et al. ${ }^{16}$, and $\mathrm{McCoy}^{18}$. assumed $\mathrm{k}$ to be independent of $\mathrm{x}$ and successfully modelled their data. Assuming $\mathrm{k}$ independent of $\mathrm{x}$ adequately describes the current experimental data.

The stoichiometric kernels are defined to satisfy normalization and symmetry conditions : 


$$
\begin{aligned}
& v\left(\mathrm{x}^{\prime}-\mathrm{x}_{1}, \mathrm{x}^{\prime}\right)=\delta\left(\mathrm{x}-\left(\mathrm{x}^{\prime}-\mathrm{x}_{1}\right)\right) \\
& v\left(\mathrm{x}_{1}, \mathrm{x}^{\prime}\right)=\delta\left(\mathrm{x}-\mathrm{x}_{1}\right)
\end{aligned}
$$

We assume that all products of the scission are completely dissolved in the solution and no repolymerization occurs. The batch reactor equation can be written as follows :

$$
\frac{d q_{1}(x, t)}{d t}=\int_{x}^{\infty} k p\left(x^{\prime}, t\right) \delta\left(x-x_{1}\right) d x^{\prime}
$$

The initial condition is

$$
q_{1}(x, 0)=0
$$

The moment operation defined as

$$
q_{1}^{(j)}(t)=\int_{0}^{\infty} x^{j} q_{1}(x, t) d x
$$

applied to equation (6) yields

$$
\frac{d q_{1}^{(j)}(t)}{d t}=k x_{1}^{j} p^{(0)}(t)
$$

This is solved with the initial condition

$$
p^{(0)}(0)=p_{0}^{(0)}
$$

For special cases for $\mathrm{j}=0,1,2$ the above equations are solved to yield

$$
\begin{aligned}
& q_{1}^{(0)}(t)=k p_{0}^{(0)} t \\
& q_{1}^{(1)}(t)=k x_{1} p_{0}^{(0)} t \\
& q_{1}^{(2)}(t)=k x_{1}^{2} p_{0}^{(0)} t
\end{aligned}
$$

The average MW and variance are calculated from the first and second moments as follows: 


$$
\begin{aligned}
& x_{1}^{\text {avg }}(t)=\frac{q_{1}^{(1)}(t)}{q_{1}^{(0)}(t)}=x_{1} \\
& \sigma_{1}^{2}(t)=\frac{q_{1}^{(2)}(t)}{q_{1}^{(0)}(t)}-\left(x_{1}^{\text {avg }}(t)\right)^{2}=0
\end{aligned}
$$

which indicate that the MWD for $\alpha$-methylstyrene is, ideally (in absence of chromatographic dispersion), a delta function and the first moment is the MW of the compound. These equations are consistent with the model derived by Wang et al. ${ }^{15}$ when the rate of random scission approaches zero $\left(\mathrm{k}_{\mathrm{r}} \rightarrow 0\right)$.

\section{Results and Discussion}

The experimental data for the degradation of PAMS at the five temperatures and three concentrations were analyzed to obtain rate coefficients at each condition. Since the reactor can be considered a steady-state plug-flow reactor, we represent time, $t$, by the residence time, $\tau=$ reactor volume/volumetric flow rate, and determine the rate coefficients for specific degradation by rewriting equation 9 ,

$$
q=k p \tau
$$

where $p$ is the molar feed concentration $(\mathrm{mol} / \mathrm{L}), \tau$ is the residence time, and $q$ is the molar concentration of the $\alpha$-methylstyrene ( $\mathrm{mol} / \mathrm{L}$ ). Molar concentration is the zeroth moment ( $g / L)$ of the MWD divided by the MW. As the zeroth moment is the area under the curve, the area of the $\alpha$-methylstyrene peak was determined by numerical integration. Only the first half of the $\alpha$-methylstyrene peak is visible because the peak of toluene overlaps the other half of the $\alpha$-methylstyrene peak. The symmetry of the $\alpha$-methylstyrene peak was tested by injecting $\alpha$-methylstyrene in the GPC. Hence the amount of $\alpha$-methylstyrene is determined by doubling the area under the half-peak of $\alpha$-methylstyrene. The plots of $q$ versus p, shown in Figures 5-6, confirm the linear relationship for the experimental 
conditions. The slope of the line gives the rate coefficient for specific degradation, $k$. The line passes through the origin confirming that there is no overlap of the toluene peak in the first half of the $\alpha$-methylstyrene peak.

The dependence of the rate coefficient on the temperature and on concentration of the polymer is shown in the Tables 1-2. Figure 7 and Table 2 show that the rate constants are independent of polymer concentration, confirming that the reaction for PAMS to $\alpha-$ methylstyrene is first-order at $150 \mathrm{C}$. The rate-coefficient dependence on temperature is shown in Figure 8, where the slope of the line corresponds to an activation energy of 66.5 $\mathrm{kJ} / \mathrm{mol}$ for the degradation of PAMS to $\alpha$-methylstyrene.

An estimate of $1.2 \%$ for the conversion of PAMS to $\alpha$-methylstyrene at $275 \mathrm{C}$ and $\tau=$ 23.8 min was obtained by the following formula:

Conversion $=\left(\frac{\mathrm{p}_{\mathrm{o}}^{(1)}-\mathrm{p}^{(1)}(\tau)}{\mathrm{p}_{\mathrm{o}}^{(1)}}\right) \times 100 \%$

The first moment of the molar distribution is the mass oncentration the above equation represents conversion based on the fractional weight loss.

There was no effect of the hydrogen-donor solvent, tetralin, on the degradation of PAMS to $\alpha$-methylstyrene at $225 \mathrm{C}$. This is consistent with the results of Murakata et al. ${ }^{13}$ who observed that there was no effect of solvent on the degradation of PAMS.

\section{Conclusion}

The thermal degradation of solubilized PAMS (in toluene) in a steady-state, tubular-flow reactor was studied at various polymer concentrations and temperatures. The results are interpreted by considering that the polymer degrades by chain-end scission to $\alpha$ methylstyrene. A continuous-mixture model was used to quantify the experimental data and 
determine rate constants. The effect of temperature on the rate coefficients was significant with an activation energy of $66.5 \mathrm{~kJ} / \mathrm{mol}(16 \mathrm{kcal} / \mathrm{mol})$. There was no effect of the hydrogen donor solvent, tetralin, on the degradation.

\section{Acknowledgement}

The financial support of Pittsburgh Energy Technology Center Grant No. DOE DEFG22-94PC94204 and EPA Grant No. CR 822990-01-0 is gratefully acknowledged. 


\section{References}

I. Allen, N.S. \& Edge, M. Fundamentals of Polymer Degradation and Stabilization, Elsevier Applied Science, New York, 1966.

2. Miller, A., Environ. Sci. Tech., 28 (1994), 16A.

3. Flynn, J.H. \& Florin, R.E. In Pyrolysis and GC in Polymer Analysis, Liebman, S. A. \& Levy, E.J., Eds., Marcel Dekker Inc., New York, 1985, p. 149.

4. Jellinek, H.H.G., Degradation and Vinyl Polymers, Academic Press, New York, 1955.

5. Simha, R., \& Wall, L.A. In Catalysis, Vol. 6, Rienhold, New York, 1958, Chapter 3.

6. Reich, L., \& Stivala, S.S Elements of Polymer Degradation, McGraw-Hill, New York, 1971, p. 164.

7. Hawkins, W. L., Polymer Degradation and Stabilization, Springer-Verlag, New York, 1984.

8. Kehlen, H., Ratzsch, M.T. \& Bergmann, J., Chem. Eng. Sci., 43 (1988), 609.

9. Jellinek, H.H.G., Degradation and Stabilization of Polymers, Vol. 1, Elsevier, New York, 1983.

10. Ziff, R. M. \& McGrady, E.D., J. Phys. A: Math. Gen., 18 (1985), 3027.

11. Inaba, A. \& Inoue, H., Kagaku kagaku Ronbunsyu, 5 (1979), 243.

12. Sato, S., Murakata, T., Baba, S., Saito, Y.\& Watanabe, S., J. Appl. Poly. Sci., 40 (1990), 2065.

13. Murakata, T., Saito, Y., Yosikawa, T., Suzuki, T. \& Sato, S., Polymer, 34 (1993), 1436.

14. Murakata, T., Wagatsuma, S., Saito, Y., Suzuki, T. \& Sato, S., Polymer, 34 (1993), 1431.

15. Wang, M., Smith, J.M. \& McCoy, B.J., AlChE J., 41 (1995), 1521.

16. Madras, G., Smith, J.M. \& McCoy, B.J., Ind. Eng. Chem. Res., (1995), in press.

17. Wang, M., Zhang, C.J., Smith, J.M.\& McCoy, B.J., AIChE J., 40 (1994), 131.

18. McCoy, B. J., AIChE J., 39 (1993), 1827.

19. Kamide, K., \& Matsuda, S., In Determination of Molecular Weight, Cooper, A.R., Ed., John Wiley \& Sons, New York, 1989, p. 201.

20. Zhang, C. J., Smith, J.M. \& McCoy, B.J., In ACS Symposium Series on Supercritical Fluids, No. 514, Chap. 29, 1992; p. 386.

21. Wang, M., Smith, J.M. \& McCoy, B.J., Energy \& Fuel, 7(1993), 78.

22. Lee, B.F. \& Kesler, M.G., AIChE. J., 21 (1975), 510.

23. Moore, G.R., \& Kline, D.E., Properties and Processes of Polymers for Engineers, PrenticeHall, Inc., NJ, 1984. 
Table 1. Rate coefficients for degradation of PAMS to $\alpha$-methylstyrene at various temperatures at a constant polymer concentration of $2.00 \mathrm{~g} / \mathrm{L}$.

\begin{tabular}{|l|l|}
\hline $\begin{array}{l}\text { Temperature } \\
(C)\end{array}$ & $\begin{array}{l}\mathrm{k}\left(\mathrm{x} 10^{3}\right) \\
(1 / \mathrm{min})\end{array}$ \\
\hline 150 & 1.04 \\
\hline 175 & 2.3 \\
\hline 200 & 2.8 \\
\hline 225 & 10.6 \\
\hline 275 & 85.3 \\
\hline
\end{tabular}


Table 2. Rate coefficients for degradation of PAMS to $\alpha$-methylstyrene at various polymer concentration at constant temperature of $150 \mathrm{C}$.

\begin{tabular}{|l|l|}
\hline $\begin{array}{l}\text { Polymer Conc. } \\
(\mathrm{g} / \mathrm{L})\end{array}$ & $\begin{array}{l}\mathrm{k}\left(\mathrm{x} 10^{3}\right) \\
(1 / \mathrm{min})\end{array}$ \\
\hline 2.00 & 1.04 \\
\hline 4.00 & 1.03 \\
\hline 20.0 & 1.07 \\
\hline
\end{tabular}




\section{Figure captions}

1. MWD of untreated PAMS.

2. MWD of treated PAMS.

3. Experimental results of MWD at $473 \mathrm{~K}, 6.8 \mathrm{MPa}$, and $\tau=23.8 \mathrm{~min}$.

4. MWDs before and after thermal degradation at $473 \mathrm{~K}, 6.8 \mathrm{MPa}$, and $\tau=23.8 \mathrm{~min}$.

5. Plots of the ratio, $q / p$, for $\alpha$-methylstyrene at various temperatures with constant polymer concentration $(2.00 \mathrm{~g} / \mathrm{L})$.

6. Plots of the ratio, $q / p$, for $\alpha$-methylstyrene at various polymer concentrations at a constant temperature $(150 \mathrm{C})$

7. Plot of polymer concentration versus specific rate constant indicating first-order dependence.

8. Arrhenius plot for specific degradation rate constant. 
Figure 1

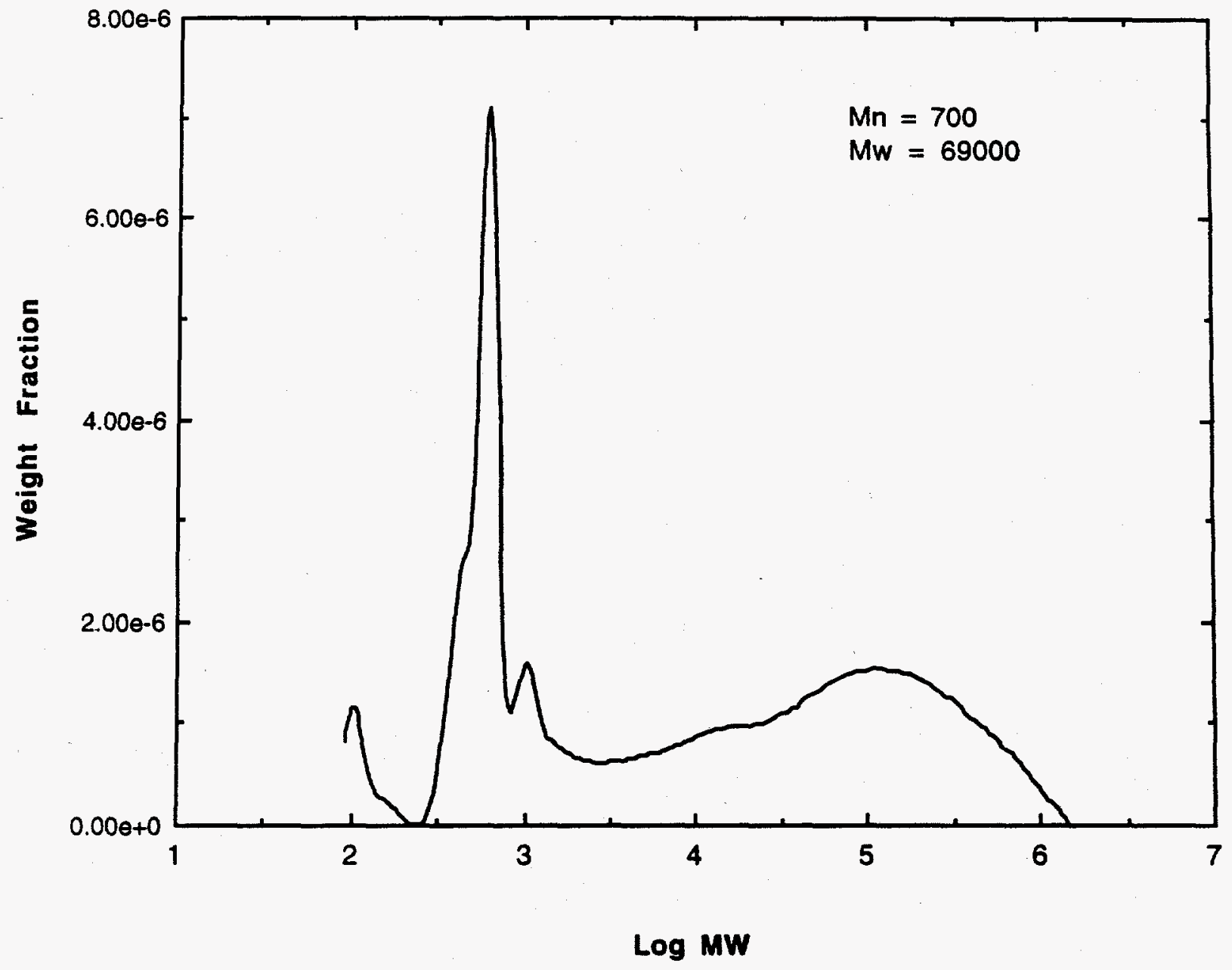


Figure 2

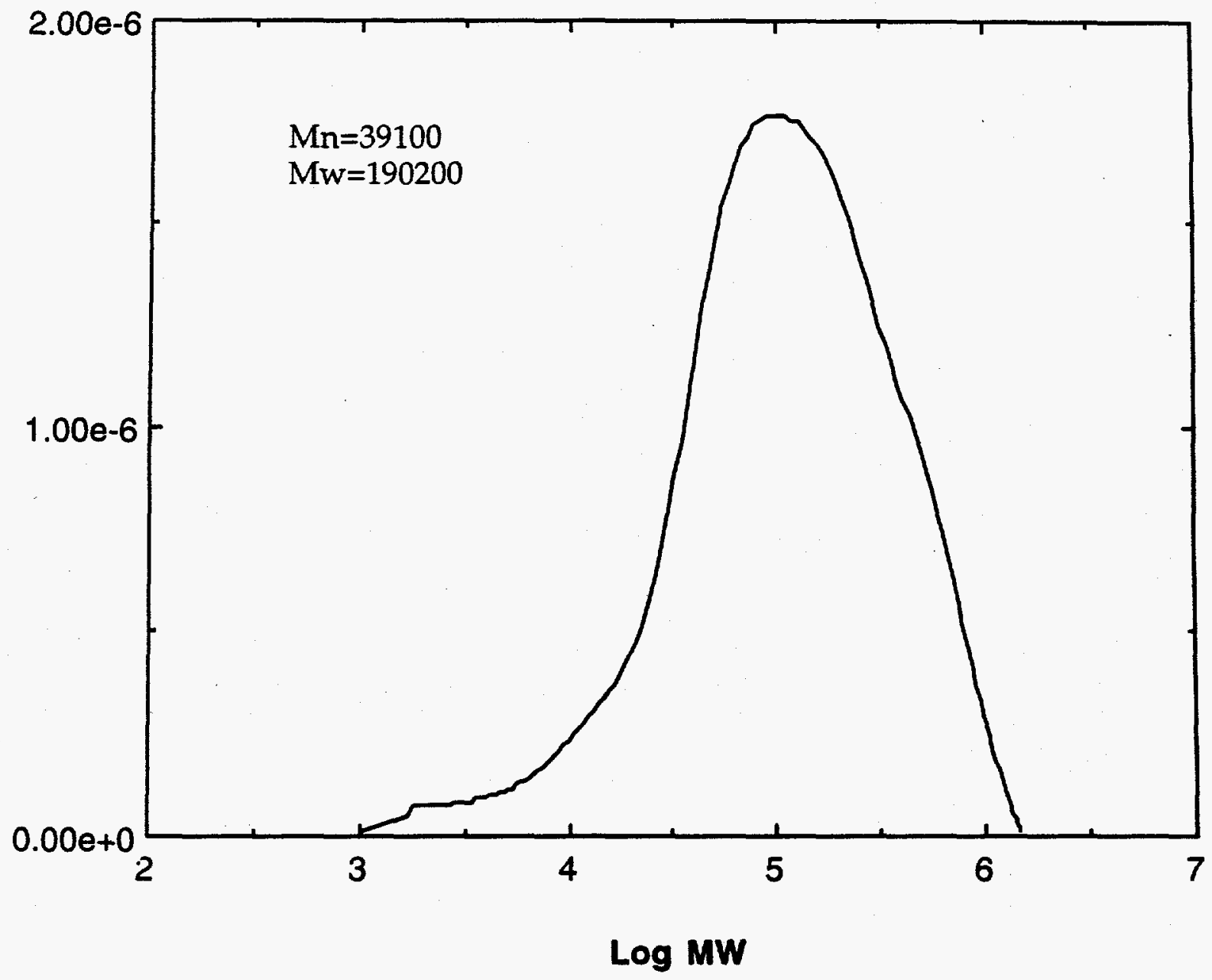


Finge 3

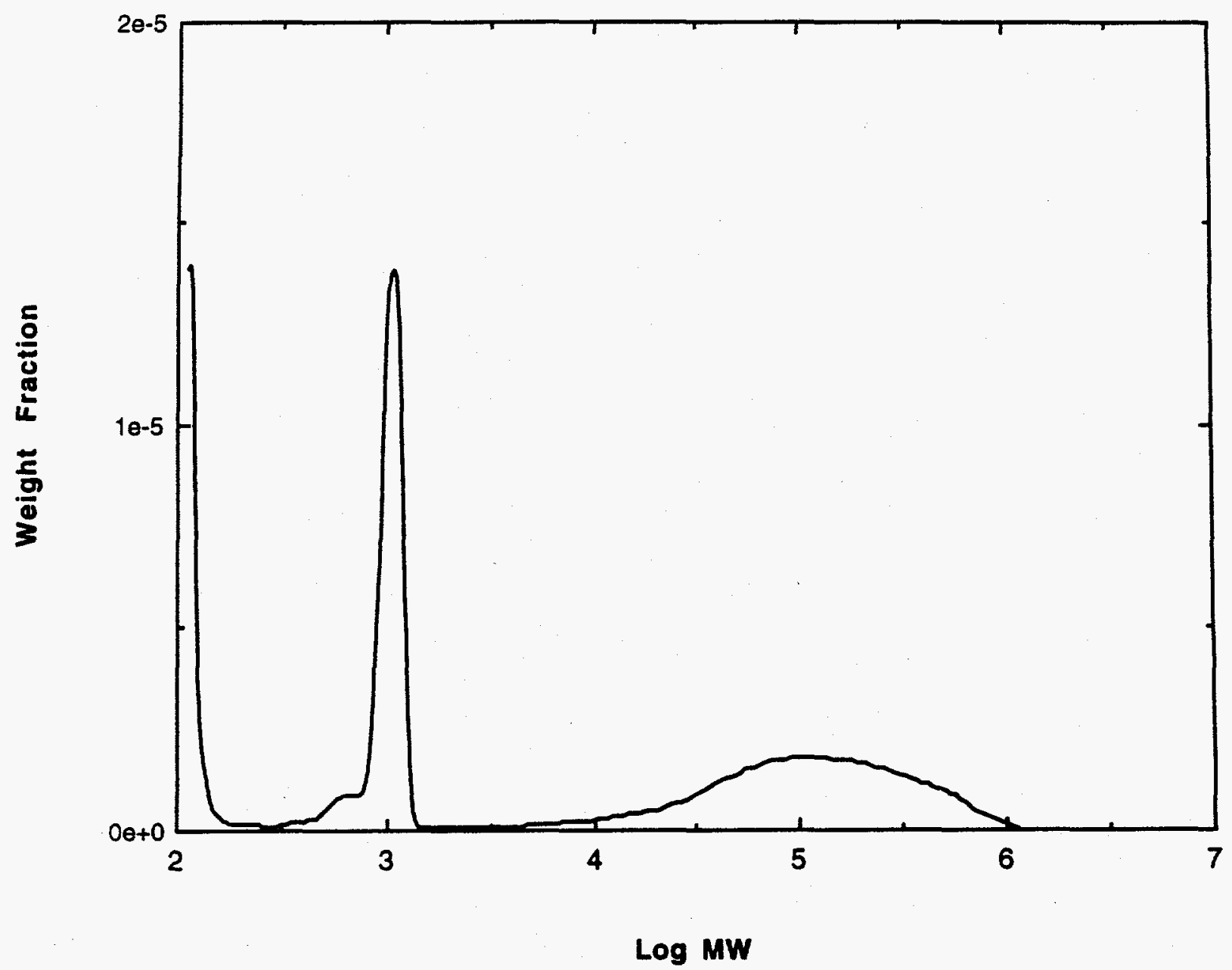


Figare 4

\section{….... Before Experiment - After Experiment}

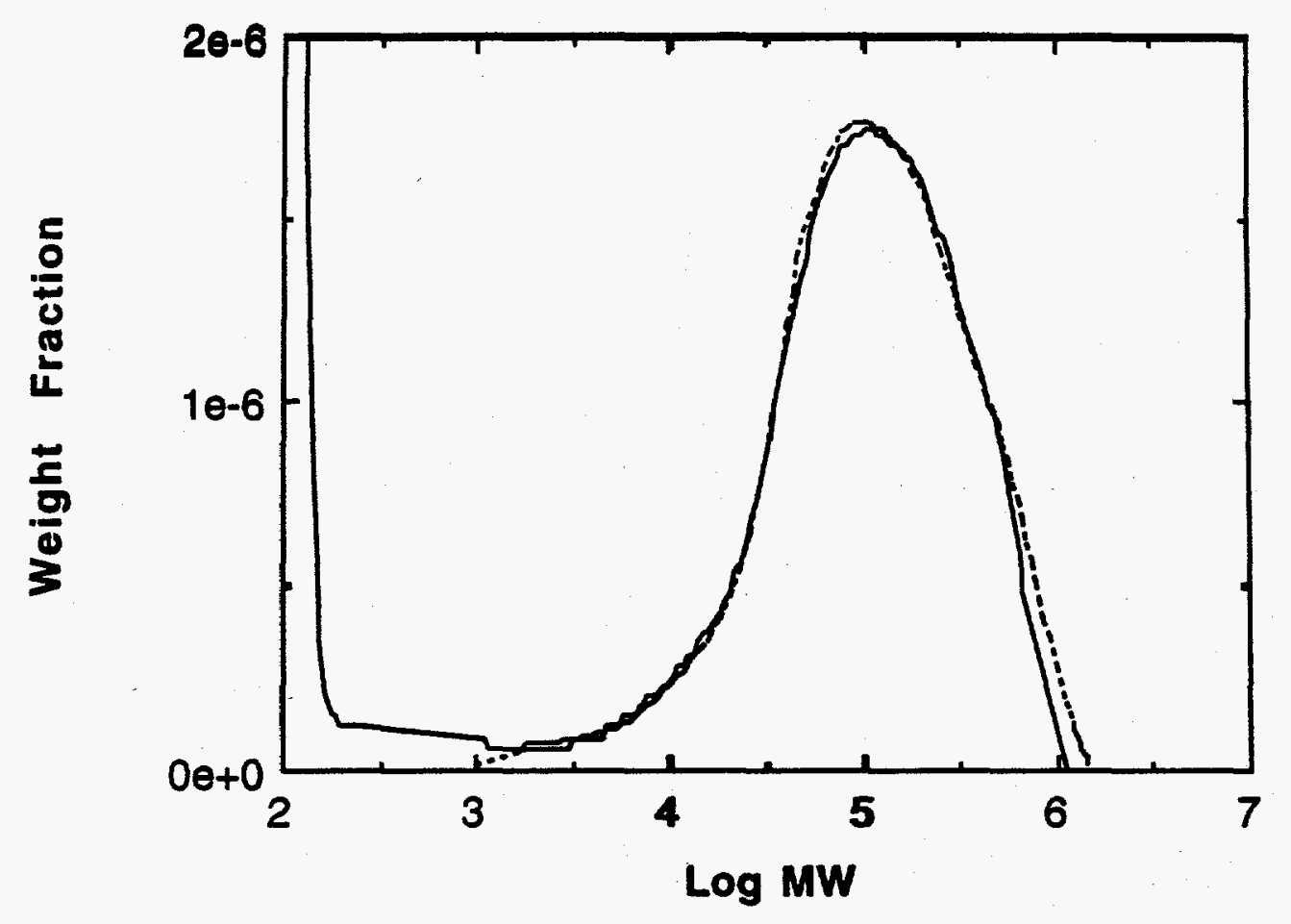


Figure 5

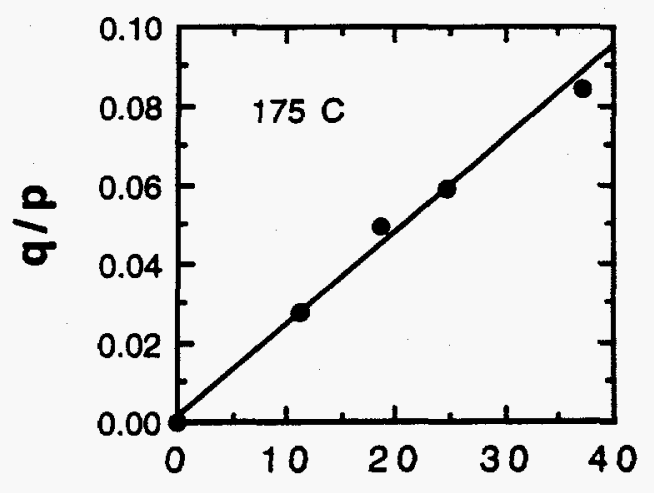

Time, min

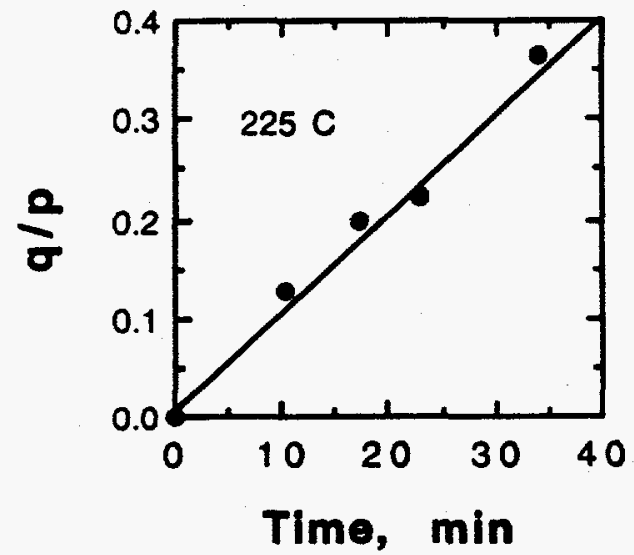

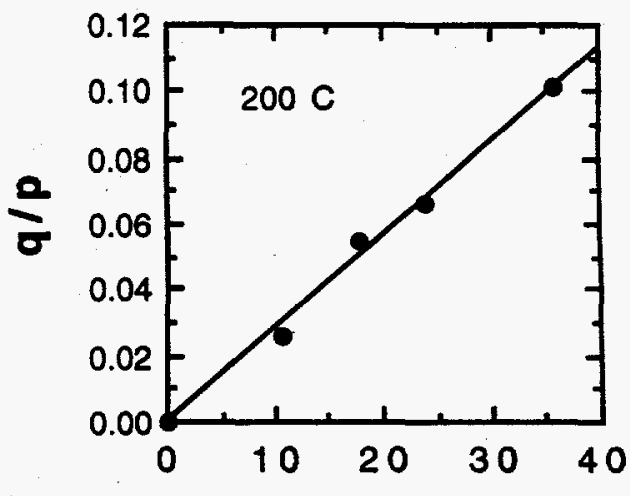

Time, min

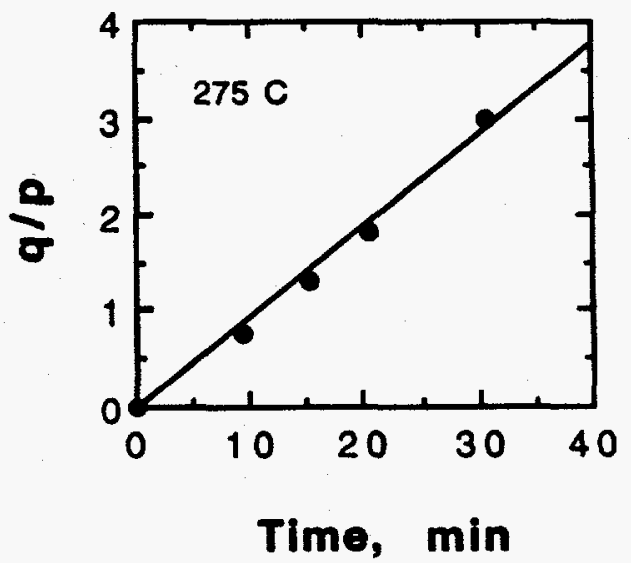


Figure:
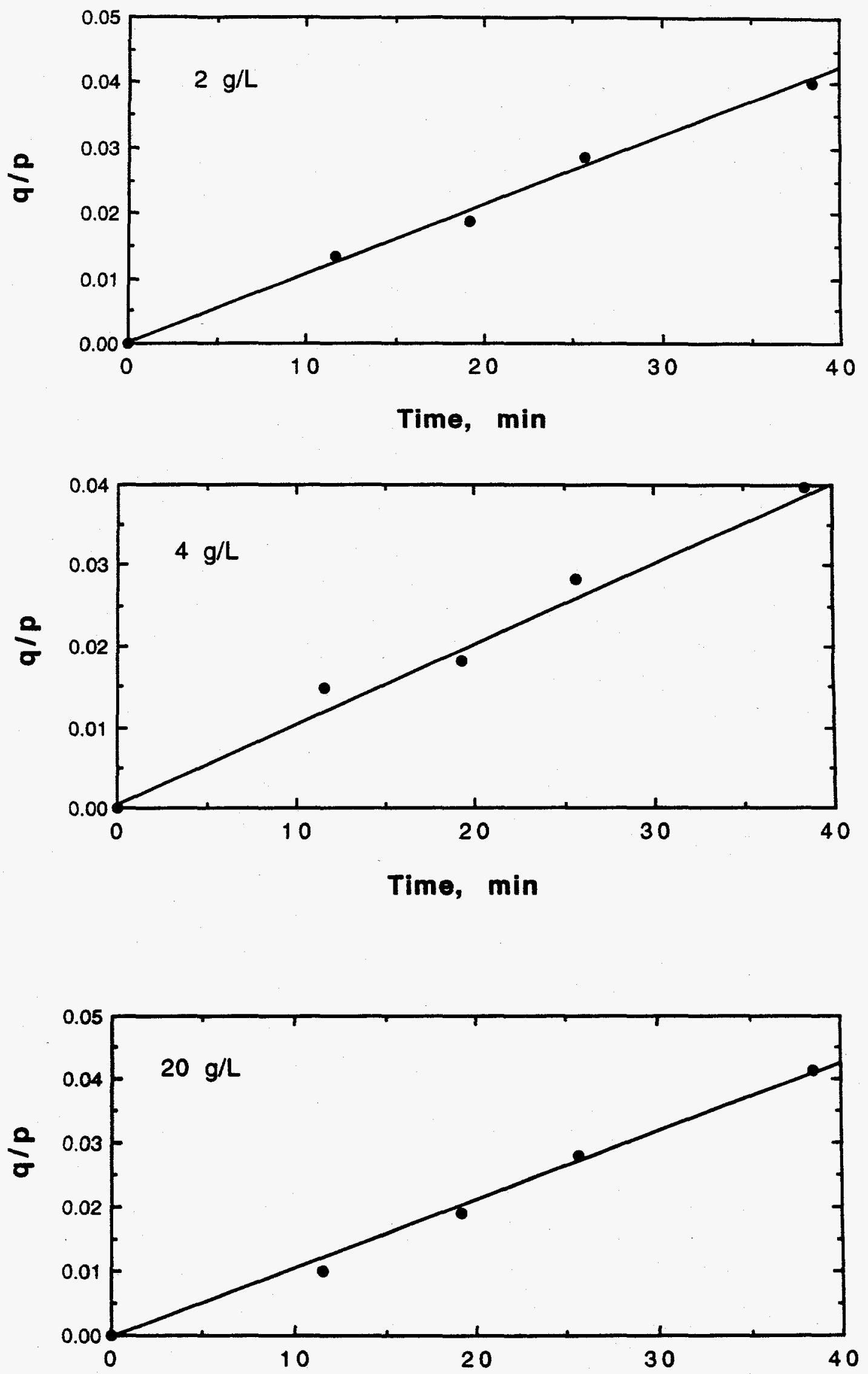

Time, min 
Figure 7

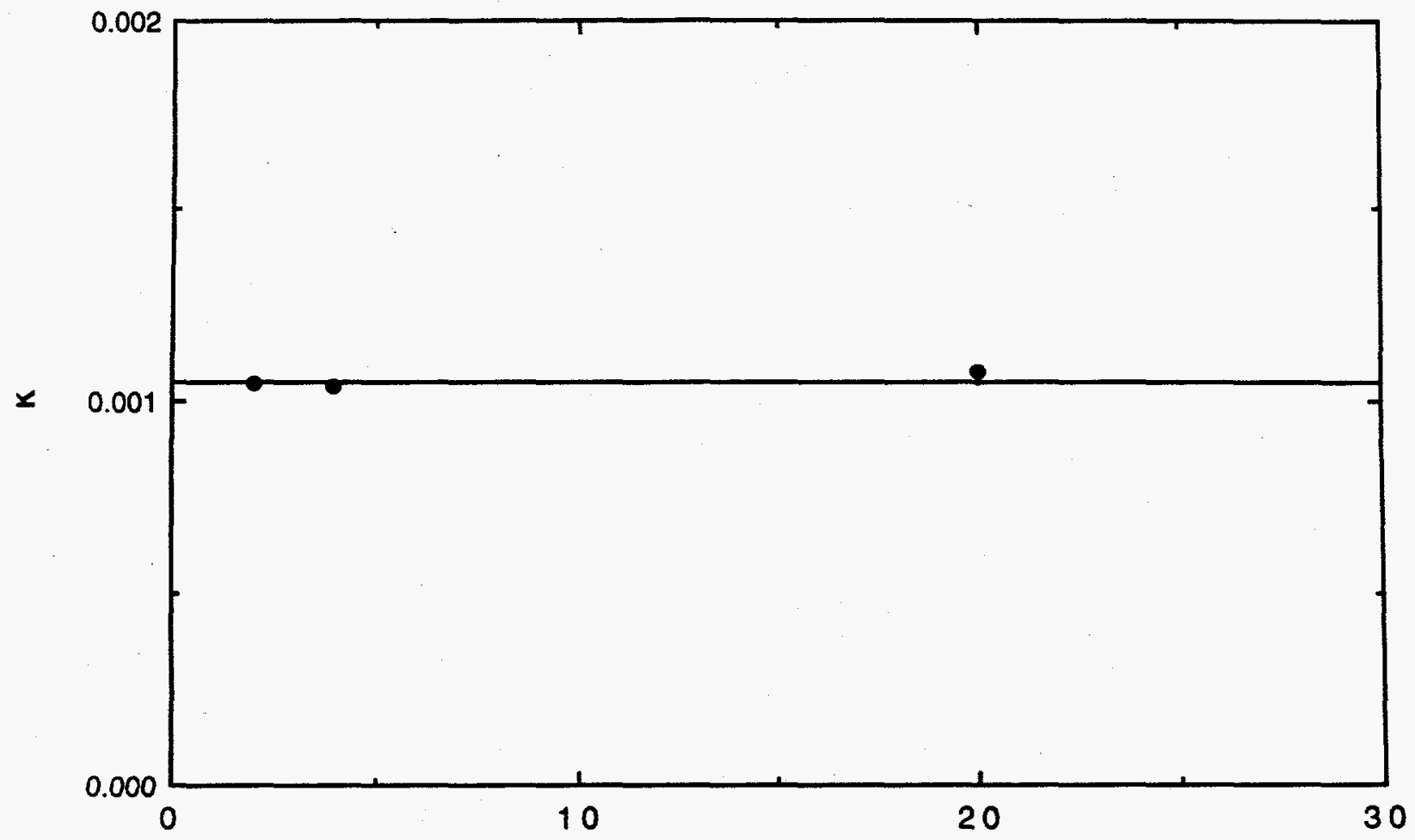

Polymer concentration ( $g / L)$ 
Figure 8

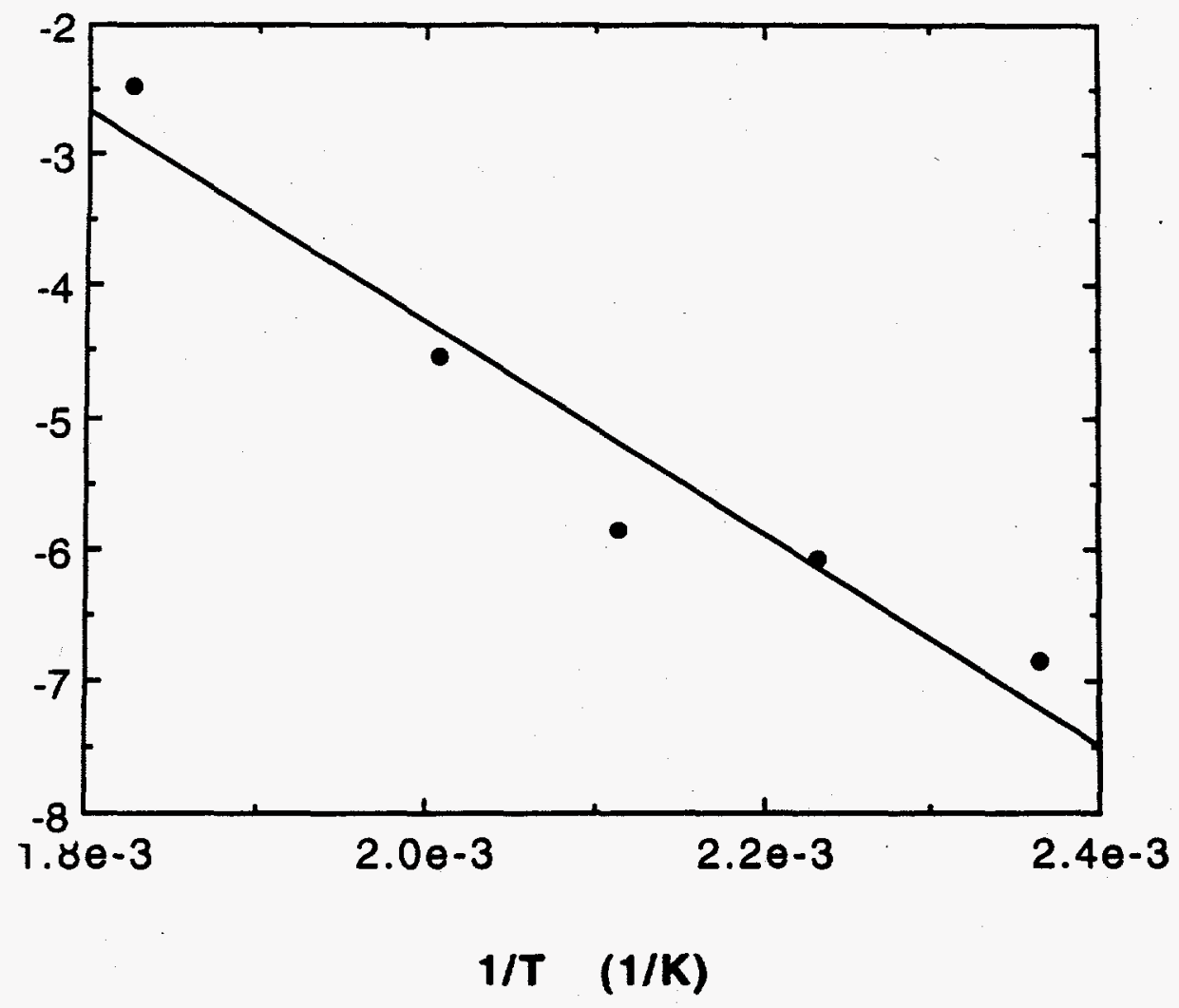

